\title{
Transient Severe Motion Artifact Related to Gadoxetate Disodium-Enhanced Liver MRI: Frequency and Risk Evaluation at a German Institution
}

\author{
Transiente schwere Atemartefakte bei \\ Dinatriumgadoxetat-gestützter MRT: Häufigkeit \\ und Risikoevaluation an einer deutschen Klinik
}

Authors

Lennart Well, Vanessa Hanna Rausch, Gerhard Adam, Frank Oliver Henes, Peter Bannas

\section{Affiliation}

Department for Diagnostic and Interventional Radiology and Nuclear Medicine, University Medical Center Hamburg-

Eppendorf, Hamburg, Germany

Key words

contrast agents, transient severe motion artifact, MR, gadoxetate disodium, magnetic resonance imaging, transient se-

vere artifacts, risk

received 8.6.2016

accepted 11.1.2017

Bibliography

DOI http://dx.doi.org/10.1055/s-0043-102940

Published online: 26.4.2017 | Fortschr Röntgenstr 2017; 189 : 651-660 @ Georg Thieme Verlag KG Stuttgart · New York ISSN 1438-9029

Correspondence

Dr. Lennart Well

Department of Diagnostic and Interventional Radiology and Nuclear Medicine Hamburg, University Medical Center Hamburg-Eppendorf

Martinistrasse 52

20251 Hamburg

Germany

Tel.: ++ 49/40/15222816145

I.well@uke.de

\section{ZUSAMMENFASSUNG}

Ziel Das Auftreten kontrastmittelinduzierter, transienter schwerer Atemartefakte (TSA) nach Applikation von Dinatriumgadoxetat wurde mit einer variablen Inzidenz (5-18\%) beschrieben. Da bisherige Studien aus den USA und Japan stammen, war es unser Ziel die Inzidenz der TSA an einem deutschen Institut zu ermitteln, potentielle Risikofaktoren zu bestimmen und unsere mit bisherigen Studienergebnissen zu vergleichen.
Material und Methoden In unserer retrospektiven unizentrischen Studie wurden zwei alters- und geschlechtsabgestimmte Gruppen aus dem Kollektiv der in unserer Klinik angefertigten, kontrastmittelgestützten MRT-Untersuchungen bestimmt. (Dinatriumgadoxetat $n=89$; Gadobenat Dimeglumin $n=89$ ). Zwei gegenüber dem verwendeten Kontrastmittel geblindete Radiologen bewerteten unabhängig die atemabhängigen Bewegungsartefakte in nativen und dynamischen Kontrastmittelphasen auf einer 4-Punkte Skala. Werte von $\geq 3$ wurden als schwere Artefakte angesehen. Wenn zudem Atemartefakte in allen anderen Untersuchungsphasen mit Werten $<3$ bewertet wurden, erfolgte eine Einstufung der Artefakte als TSA. Eine Korrelation von potentiellen Risikofaktoren und TSA erfolgte mittels logistischer Regression.

Ergebnisse Nach Injektion von Dinatriumgadoxetat zeigten sich signifikant mehr atemabhängige Bewegungsartefakte in den arteriellen $(2,2 \pm 0,9)$ Kontrastmittelphasen als in allen anderen Phasen $(1,6 \pm 0,7)(p<0,05)$. Die Häufigkeit der TSA nach Gabe von Dinatriumgadoxetat ( $n=19 ; 21,1 \%$ ) war signifikant höher als nach Gabe von Gadobenat Dimeglumin $(n=1 ; 1,1 \%)(p<0,001)$. Die Häufigkeit der TSA in unserer Klinik ist vergleichbar mit der in einigen, aber nicht allen bisher veröffentlichten Studien. Es konnte keine signifikante Korrelation von TSA und den erhobenen potentiellen Risikofaktoren ermittelt werden (alle $p>0,05$ ).

Schlußfolgerung Wir konnten ein hohes Auftreten von TSA an einer deutschen Institution demonstrieren und somit die Bedeutung eines Diagnose limitierenden Phänomens untermauern, welches bisher nur in den USA oder Japan beschrieben wurde. Ebenso wie bisherige Studien konnten wir keine Korrelation von TSA mit potentiellen Risikofaktoren identifizieren.

\section{Kernaussagen:}

- Dinatriumgadoxetat führt bei bis zu einem Fünftel der Patienten zu TSA.

- Die Häufigkeit der TSA in Deutschland, den USA und Japan ist vergleichbar.

- Weder unsere noch vorherige Studien konnten übereinstimmende Risikofaktoren für TSA identifizieren. 


\section{ABSTRACT}

Purpose Varying frequencies (5-18\%) of contrast-related transient severe motion (TSM) imaging artifacts during gadoxetate disodium-enhanced arterial phase liver MRI have been reported. Since previous reports originated from the United States and Japan, we aimed to determine the frequency of TSM at a German institution and to correlate it with potential risk factors and previously published results.

Materials and Methods Two age- and sex-matched groups were retrospectively selected (gadoxetate disodium $n=89$; gadobenate dimeglumine $n=89$ ) from dynamic contrast-enhanced MRI examinations in a single center. Respiratory motion-related artifacts in non-enhanced and dynamic phases were assessed independently by two readers blinded to contrast agents on a 4-point scale. Scores of $\geq 3$ were considered as severe motion artifacts. Severe motion artifacts in arterial phases were considered as TSM if scores in all other phases were $<3$. Potential risk factors for TSM were evaluated via logistic regression analysis.

Results For gadoxetate disodium, the mean score for respiratory motion artifacts was significantly higher in the arterial phase $(2.2 \pm 0.9)$ compared to all other phases (1.6 \pm 0.7$)$ $(p<0.05)$. The frequency of TSM was significantly higher with gadoxetate disodium $(n=19 ; 21.1 \%)$ than with gadobenate dimeglumine $(n=1 ; 1.1 \%)(p<0.001)$. The frequency of TSM at our institution is similar to some, but not all previously published findings. Logistic regression analysis did not show any significant correlation between TSM and risk factors (all $p>0.05)$.

Conclusion We revealed a high frequency of TSM after injection of gadoxetate disodium at a German institution, substantiating the importance of a diagnosis-limiting phenomenon that so far has only been reported from the United States and Japan. In accordance with previous studies, we did not identify associated risk factors for TSM.

\section{Key Points:}

- Gadoxetate disodium causes TSM in a relevant number of patients.

- The frequency of TSM is similar between the USA, Japan and Germany.

- To date, no validated risk factors for TSM could be identified.

\section{Citation Format}

- Well L, Rausch VH, Adam G et al. Transient Severe Motion Artifact Related to Gadoxetate Disodium-Enhanced Liver MRI: Frequency and Risk Evaluation at a German Institution. Fortschr Röntgenstr 2017; 189: 651-660

\section{Introduction}

Gadoxetate disodium (Primovist/Eovist; Bayer Healthcare, Wayne, NJ, USA) and gadobenate dimeglumine (Multihance, Bracco Imaging SpA, Milan, Italy) have been established as important gadolinium-based contrast agents in the clinical routine with favorable safety profiles [1 -5]. Due to the hepatic uptake and biliary excretion, gadoxetate disodium has become an essential diagnostic tool for hepatobiliary phase imaging and specific indications such as the evaluation of hepatocellular carcinoma (HCC) $[6,7]$, identification of hepatic metastases [8-10] or characterization of biliary diseases [11]. For a sufficient diagnostic yield of liver MRI, dynamic phases with arterial, venous and delayed timing have to be obtained. The acquisition of arterial phases is of particular importance for the characterization of hypervascularized lesions such as HCC [12 - 14].

Unfortunately, the application of gadoxetate disodium can lead to transient and partially severe dyspnea during arterial phase imaging. Consecutively, transient severe motion-related artifacts (TSM) might render examinations non-diagnostic [15]. The frequency of TSM in previous studies ranged from $11-22 \%$ $[16,17]$. Several authors were able to identify significant correlations with TSM and potential risk factors such as pulmonary disease, volume of injected contrast agent [18], repeated dosing [19] as well as high body weight or male sex [17]. However, these findings are not consistent between published articles [20]. Published data regarding TSM stem mostly from the United States of America (USA) and Japan [15 - 17, 20, 21].
Therefore, we aimed to determine the frequency of transient respiratory motion artifacts with gadoxetate disodium and gadobenate dimeglumine at a German institution. We correlate these artifacts with potential risk factors and compare our findings with previously published studies to work out the clinical implications of this diagnosis-limiting imaging artifact.

\section{Materials and Methods}

\section{Study Population}

The local institutional review board approved our retrospective single-center study and waived the requirement for informed consent. The study population was chosen from $n=559$ consecutive patients that underwent hepatic MRI with application of gadoxetate disodium $(n=458)$ or gadobenate dimeglumine $(n=101)$ between January 2015 and June 2016 in our clinic. From this population, $n=284$ patients were excluded (gadoxetate disodium $n=272$ and gadobenate dimeglumine $n=12$ ). Exclusion criteria were previous exposure to the other contrast agent (gadoxetate disodium $n=45$ and gadobenate dimeglumine $n=3$ ), missing information on patient characteristics and potential risk factors (gadoxetate disodium $\mathrm{n}=226$ and gadobenate dimeglumine $\mathrm{n}=8$ ) or severe non-respiratory motion-related imaging artifacts (gadoxetate disodium $n=1$ and gadobenate dimeglumine $n=1$ ). Finally, from the remaining group of $n=275$ patients (gadoxetate disodium $n=186$ and gadobenate dimeglumine $n=89$ ), age- and sex-matched groups ( $n=89$ for gadoxetate disodium; $n=89$ ga- 
- Table 1 Patient characteristics and potential risk factors.

- Tab. 1 Patientencharakteristika und potentielle Risikofaktoren.

\begin{tabular}{|c|c|c|c|}
\hline characteristics & gadoxetate disodium ( $n=89$ ) & gadobenate dimeglumine $(n=89)$ & p-value \\
\hline \multicolumn{4}{|l|}{ sex } \\
\hline " male & $51(57.3 \%)$ & $51(57.3 \%)$ & $>0.99$ \\
\hline - female & $38(42.7 \%)$ & $38(42.7 \%)$ & $>0.99$ \\
\hline mean age (years) & $55.2 \pm 15.2(22-82)$ & $55.2 \pm 15.2(22-82)$ & $>0.99$ \\
\hline mean body mass index $\left(\mathrm{kg} / \mathrm{m}^{2}\right)$ & $26.3 \pm 4.8(17.6-38.6)$ & $25.7 \pm 7.9(14.9-61.7)$ & 0.204 \\
\hline mean volume of contrast agent (ml) & $8.08 \pm 1.7(4-12)$ & $10.0 \pm 2.5(6-17)$ & $<0.001$ \\
\hline ascites & $7(7.9 \%)$ & $3(3.4 \%)$ & 0.329 \\
\hline pleural effusions & $3(3.4 \%)$ & $4(4.5 \%)$ & $>0.99$ \\
\hline lung disease & $9(10.1 \%)$ & $7(7.9 \%)$ & 0.794 \\
\hline previous exposure to contrast agent & $22(24.7 \%)$ & $46(51.7 \%)$ & 0.002 \\
\hline allergies & $17(19.1 \%)$ & $22(24.7 \%)$ & 0.719 \\
\hline liver disease & $22(24.7)$ & $5(5.6 \%)$ & 0.006 \\
\hline hepatocellular carcinoma & $13(14.6 \%)$ & $0(0 \%)$ & 0.016 \\
\hline hypertension & $29(32.6 \%)$ & $29(32.6 \%)$ & $>0.99$ \\
\hline
\end{tabular}

dobenate dimeglumine; male $n=51$; female $n=38$; median age 55 years; IQR 44.5 to 82 years in each group) were selected for further investigation.

\section{Patient Characteristics and Risk Factors}

Patient characteristics and potential risk factors were taken from the electronic medical record system. Discriminators were sex, age, weight, height, volume of injected contrast agent, occurrence of ascites, pleural effusions, lung disease, previous exposure to contrast agents, allergies (gadolinium-based contrast agents, iodinated contrast agents, other drugs, aliment, contact allergens, pollen), liver cirrhosis, hepatocellular carcinoma and hypertension ( $\triangleright$ Table 1 ). The most common indications for gadoxetate disodium were the characterization of liver masses $(n=48)$ and screening for hepatocellular carcinoma $(n=19)$. For gadobenate dimeglumine, the most common indications were the characterization of pancreatic masses $(n=15)$, pancreatitis or cholangitis $(n=12)$ or screening for hepatic masses $(n=13)$.

\section{Contrast Agent}

Patients were intravenously injected with either gadoxetate disodium or gadobenate dimeglumine during MRI examinations. Applied doses were $0.025 \mathrm{mmol} / \mathrm{kg}$ for gadoxetate disodium (mean of $8 \mathrm{ml}$, range $4 \mathrm{ml}-12 \mathrm{ml}$ ) and $0.1 \mathrm{mmol} / \mathrm{kg}$ for gadobenate dimeglumine (mean $10 \mathrm{ml}$, range $6 \mathrm{ml}-17 \mathrm{ml}$ ). Both contrast agents were injected undiluted manually at a flow rate of approximately $2 \mathrm{ml} / \mathrm{s}$ followed by a $10 \mathrm{ml}$ saline chaser.

\section{MR Image Acquisition}

Magnetic resonance examinations were performed on either a 1.5-T system (Philips Achieva, Philips Healthcare, Best, the Netherlands) ( $n=42$ for gadoxetate disodium and $n=33$ for gadobenate dimeglumine) or a 3.0-T system (Philips Intera, Philips Healthcare, Best, the Netherlands) ( $n=47$ for gadoxetate disodium and $n=56$ for gadobenate dimeglumine) with multichannel receive-only surface coils.

At 1.5 T, imaging was performed using a high-resolution isotropic volume examination (THRIVE) with the following parameters: TR/TE 3.9/1.8ms; flip angle $10^{\circ}$; FOV $330 \times 330 \mathrm{~mm}$; slice thickness $4.4 \mathrm{~mm}$. At $3 \mathrm{~T}$, imaging was performed using a multipoint Dixon sequence (mDixon) with the following parameters: TR/TE1 / TE2 3.5/1.2/2.3ms; flip angle $10^{\circ}$; FOV $400 \times 400 \mathrm{~mm}$; slice thickness $1.7 \mathrm{~mm}$. Images were acquired during breath-hold in end-inspiration. Image acquisition times ranged between 12 and 15 seconds for both field strengths depending on patient anatomy and field of view. A single arterial phase was used. Timing for arterial and consecutive phases was accomplished by manual timing ( $15 \mathrm{~s}$ post injection arterial phase, $90 \mathrm{~s}$ post injection venous phase, 5 min post injection late phase).

According to our clinical routine, patients were informed about necessary breath-holds in the pre-examination conversation. Verbal commands and breath-holding instructions from the technologist with image acquisition at end-inspiration were the same at both field strengths and for both contrast media. 

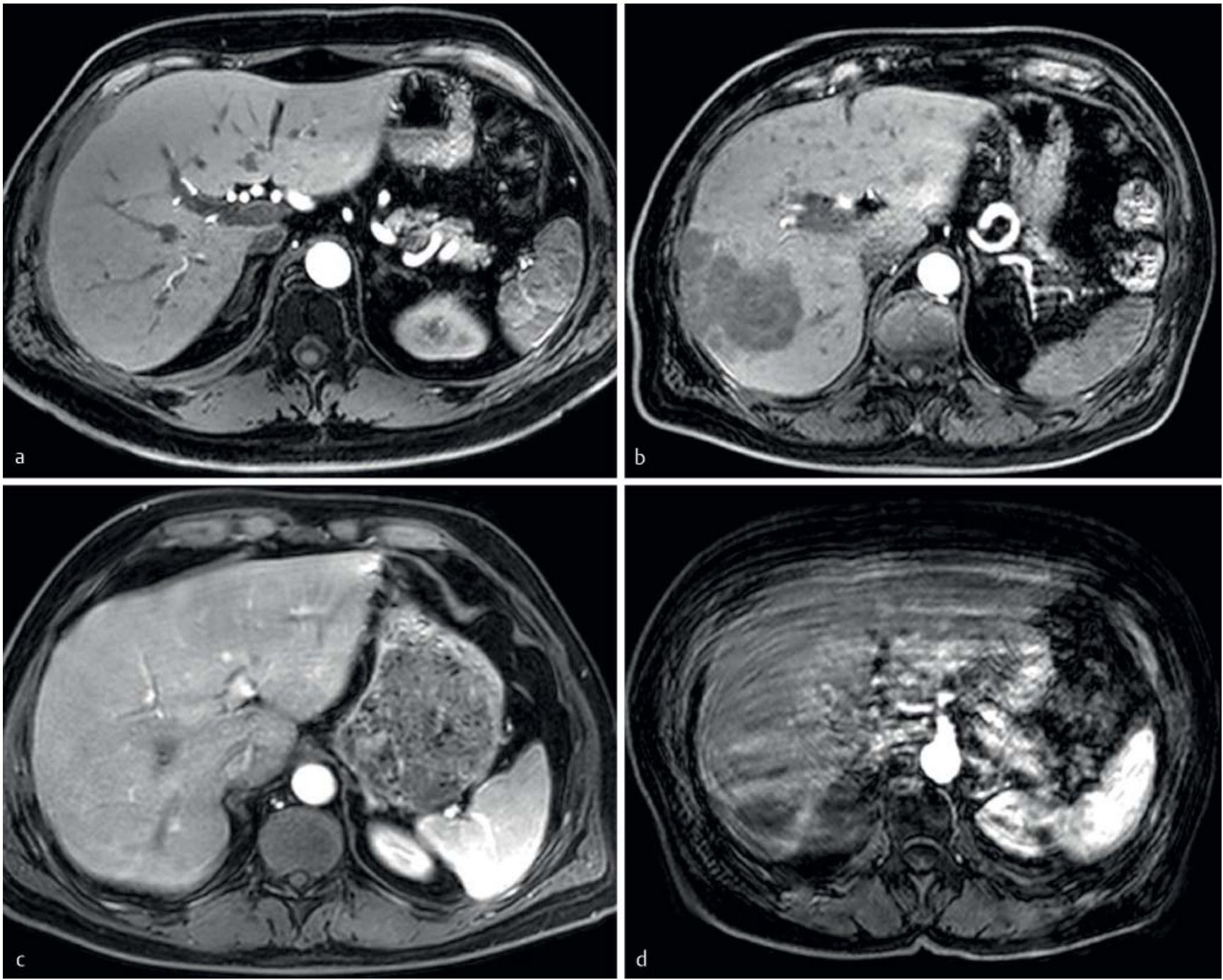

- Fig. 1 Examples of quality grading and 4-point motion score. Comparison of axial fat-saturated T1-weighted images from four different patients obtained in the arterial dynamic phase of gadoxetate disodium. The sample images show a no artifact (51-year-old man), $\mathbf{b}$ mild artifacts ( 72 -yearold man), $\mathbf{c}$ severe artifacts (45-year-old man), and $\mathbf{d}$ non-diagnostic artifacts (64-year-old woman).

- Abb. 1 Beispiele der Schweregrade der Atemartefakte und korrespondierende 4-Punkte Skala. Vergleich axialer fettgesättigter T1 Sequenzen vier verschiedener Patienten während der arteriellen Phase von Dinatriumgadoxetat mit a keinem Artefakt (51 jähriger Mann), b geringen Artefakten (72 jähriger Mann), c schweren Artefakten (45 jährigen Mann) und d diagnostisch nicht verwertbaren Artefakten (64 jährige Frau).

\section{Image Analysis}

Two radiologists, each with two years of training in abdominal MRI, performed an independent image analysis. Radiologists were blinded to the contrast agent and the patient's clinical data. Images from the non-enhanced, arterial, venous, and late phases were reviewed independently. Motion artifacts were scored by a previously established scoring system [17] as follows: 1 = no motion artifact; 2 = mild motion artifact without interference of diagnostic assessment; 3 = severe artifact with effect on diagnostic assessment; 4 = massive artifact, rendering images non-diagnostic ( $\triangleright$ Fig. $\mathbf{1}$ ). Motion scores were averaged across the two readers to create a mean motion score for each patient and phase. Average scores of $\geq 3$ were considered as severe motion artifact. TSM was considered in cases with an arterial motion score of $\geq 3$ in addition to scores of $<3$ in non-enhanced and non-arterial phase image sets ( $\triangleright$ Fig. 2 ).

\section{Statistical Analysis}

Differences in patient characteristics and risk factors were assessed via Mann-Whitney U or Fisher-exact test. The mean motion scores for each contrast agent according to phase were compared via Mann-Whitney U-test. Logistic regression analysis was performed with the following risk factors as independent variables: age, sex, body mass, ascites, pleural effusions, lung disease, previous exposure to given contrast agent, allergies, liver cirrhosis, hepatocellular carcinoma and hypertension. P-values $<0.05$ were considered statistically significant. Comparison of TSM rates and patient characteristics between studies was performed via Fisher-exact test. Interobserver agreement was 

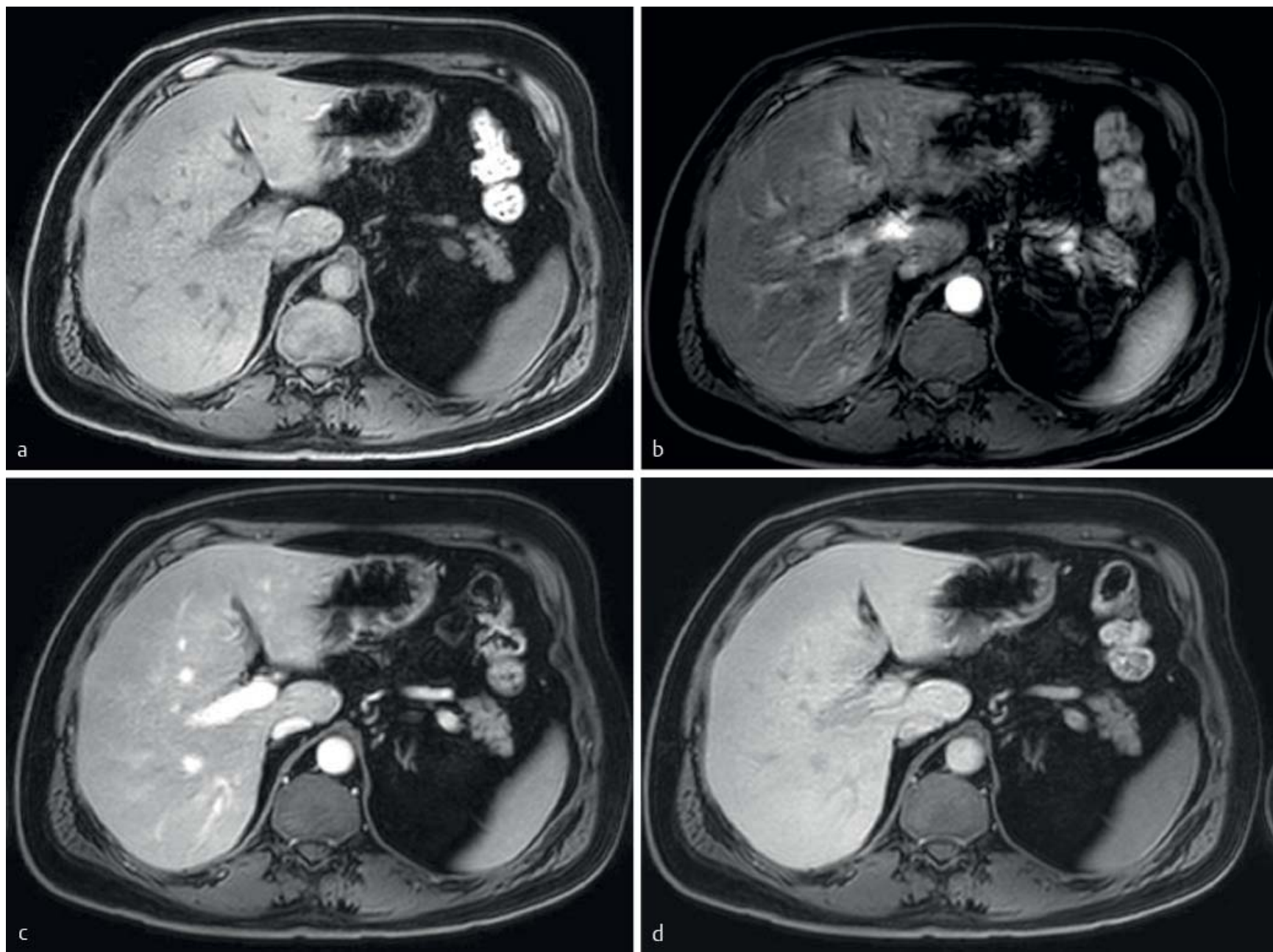

- Fig. 2 Example of transient severe respiratory motion (TSM)-related artifact after injection of gadoxetate disodium in a 49 -year-old man with germ cell tumor. Axial fat-saturated $\mathrm{T} 1$-weighted images were obtained in a pre-contrast $\mathbf{b}$ arterial $\mathbf{c}$ venous and $\mathbf{d}$ late dynamic phases. The motion score for the arterial phase was considered 4 by both readers and $<3$ for the remaining phases, resulting in the label of TSM. This patient was suffering from a lung disease (chronic obstructive pulmonary disease), which is discussed as a potential risk factor for TSM.

- Abb. 2 Beispiel eines transienten schweren Atemartefakts (TSA) nach Injektion von Dinatriumgadoxetat bei einem 49 jährigen Patienten mit Keimzelltumor. Axiale fettgesättigte T1 gewichtete Sequenzen a vor Kontrastmittelgabe, sowie in $\mathbf{b}$ arterieller, $\mathbf{c}$ venöser und $\mathbf{d}$ später Kontrastmittelphase. Die Atemartefakte in der arteriellen Phase wurden von beiden Auswertern mit 4 und in allen anderen Phasen mit $<3$ bewertet. Somit erfolgte eine Beurteilung als TSA. Der Patient litt an einer Lungenerkrankung (chronisch obstruktive Lungenerkrankung), welche als potentieller Risikofaktor für TSA diskutiert wird.

evaluated via Cohen's Kappa. Statistical analysis was performed with GraphPad Prism, version 5.01 (GraphPad Software, Inc., La Jolla, CA, USA) and SPSS for Windows, version 22 (IBM, Armonk, NY, USA).

\section{Results}

Patient characteristics and potential risk factors showed significant differences between the two study groups in regards to the mean volume of applied contrast agent $(8.1 \mathrm{ml}$ of gadoxetate disodium vs. $10.0 \mathrm{ml}$ of gadobenate dimeglumine; $\mathrm{p}<0.001$ ), the incidence of liver cirrhosis ( $25 \%$ for gadoxetate disodium vs. $6 \%$ for gadobenate dimeglumine; $p=0.006$ ), previous exposure to the applied contrast agent ( $25 \%$ vs. $51 \%$; $=0.002$ ), and the incidence of hepatocellular carcinoma ( $15 \%$ vs. $0 \%$; $p=0.016$ ). No significant differences were present for body mass index (26.3 for gadoxetate disodium vs. 25.6 for gadobenate dimeglumine; $p=0.204$ ), ascites ( $8 \%$ vs. $4 \% ; p=0.329$ ), pleural effusions ( $3 \%$ vs. $5 \%$; $p>0.99$ ), lung disease ( $10 \%$ vs. $8 \% ; p=0.794)$, allergies ( $19 \%$ vs. $25 \%$; $p=0.719$ ) or hypertension ( $33 \%$ vs. $33 \%$; p > 0.99) ( $\triangleright$ Table 1). None of the patients from the gadoxetate disodium group had an allergy to gadolinium-based contrast agents or iodinated contrast agents. In the gadobenate dimeglumine group, no patient had an allergy to gadolinium-based contrast agents while five patients had an allergy to iodinated contrast agents.

The mean motion score for gadoxetate disodium was significantly higher for arterial phase imaging (2.2) than for pre-contrast (1.7, $p=0.0004)$, venous $(1.6, p<0.0001)$ and late-phase $(1.5$, 

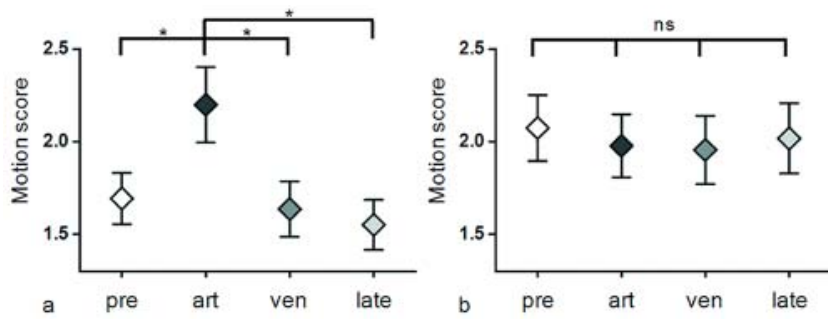

- Fig. 3 Mean motion scores of pre-contrast and dynamic phases after injection of a gadoxetate disodium and $\mathbf{b}$ gadobenate dimeglumine. For gadoxetate disodium the mean motion score was significantly higher for arterial phase imaging than for pre-contrast, venous, and late-phase imaging. Interestingly, gadobenate dimeglumine showed a relatively high mean motion score in all phases, even in the pre-contrast phase, however without significant differences between phases. Ns = non significant; ${ }^{*}=$ significant at $p<0.05$. Results are expressed as means $\pm 95 \%$ confidence intervals.

- Abb. 3 Durchschnittliche Bewertung der Atemartefakte vor Kontrastmittelgabe und in den dynamischen Phasen nach Injektion von a Dinatriumgadoxetat oder $\mathbf{b}$ Gadobenat Dimeglumin. Es zeigt sich ein signifikant höheres Auftreten von Atemartefakten nach Gabe von Dinatriumgadoxetat in der arteriellen Kontrastmittelphase im Vergleich zu der nativen, venösen und späten Kontrastmittelphase. In der Gruppe von Gadobenat Dimeglumin zeigte sich ein relativ hohes Ausmaß von Bewegungsartefakten in allen Phasen, sogar vor Kontrastmittelgabe, jedoch ohne signifikante Unterschiede zwischen den verschiedenen Phasen. Ns = nicht signifikant, ${ }^{*}=$ signifikant bei einem $p<0,05$. Darstellung der Ergebnisse als Mittelwerte mit $\pm 95 \%$ Konfidenzintervallen.

p < 0.0001) imaging ( $>$ Fig. 3). Gadobenate dimeglumine showed a relatively high mean motion score in all phases, however without significant differences between pre-contrast (2.1), arterial (2.0), venous (2.0), and late-phase (2.0) imaging (all $p>0.05$ ) ( $\triangleright$ Fig.3). The interobserver agreement for the rating of motion scores was high overall (kappa 0.86; $95 \% \mathrm{Cl} 0.83-0.89$ ) as well as for each of the individual imaging phases: pre-contrast (kappa 0.82 ; $95 \% \mathrm{Cl} 0.76-0.89$ ), arterial (kappa 0.89; $95 \% \mathrm{Cl} 0.84$ 0.94 ), venous (kappa $0.85 ; 95 \% \mathrm{Cl} 0.79-0.91$ ) and late phase (kappa 0.87; $95 \% \mathrm{Cl} 0.81-0.92$ ).

For gadoxetate disodium, the number of severe motion artifacts (mean scores $\geq 3$ ) was higher for the arterial phase $(n=31 /$ $89,35 \%)$ than for the other imaging phases $(n=6-9 / 89,7-$ $10 \%)$. For gadobenate dimeglumine, the number of severe motion artifacts (mean scores $\geq 3$ ) for the arterial phase $(n=17$, $19 \%)$ was comparable to the other imaging phases $(n=19-22$ ) 89, $21-25 \%$ ) ( Fig. 4, $>$ Table 2).

The frequency of TSM was significantly higher for gadoxetate disodium ( $n=19 / 89,21 \%$ ) than for gadobenate dimeglumine $(n=1 / 89,1 \%)(p<0.001)$. None of the observed patient characteristics and potential risk factors showed a statistically significant correlation with TSM (all $p \geq 0.05$ ), with only lung disease indicating a trend towards significance $(p=0.05)(\triangleright$ Table 3$)$. $\triangleright$ Table 4 summarizes our findings in comparison to the findings of previous studies.

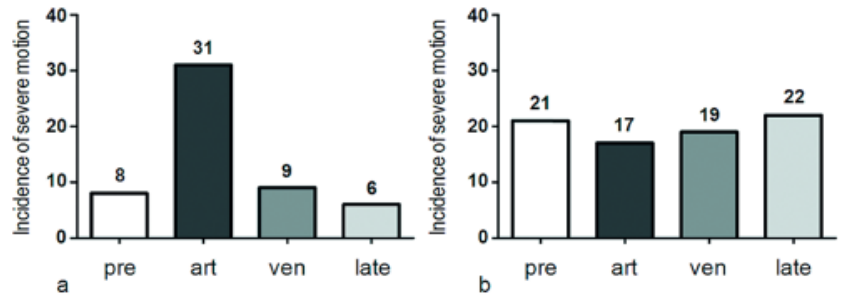

- Fig. 4 Incidence of severe motion scores (motion score of $\geq 3$ on 4-point scale) for pre-contrast and dynamic phases after injection of a gadoxetate disodium and $\mathbf{b}$ gadobenate dimeglumine. Note the high incidence of severe motion scores in the arterial phase of gadoxetate disodium compared to the overall relatively high rate for all phases of gadobenate dimeglumine.

- Abb. 4 Inzidenz schwerer Atemartefakte (Bewertung mit $\geq 3$ auf 4-Punkte Skala) vor Kontrastmittelgabe und in den dynamischen Phasen nach Injektion von a Dinatriumgadoxetat und $\mathbf{b}$ Gadobenat Dimeglumin. Beachte die hohe Inzidenz schwerer Atemartefakte in der arteriellen Phase von Dinatriumgadoxetat im Vergleich zu der insgesamt hohen Rate schwerer Atemartefakte bei Gadobenat Dimeglumin in allen Phasen.

\section{Discussion}

We demonstrated a high frequency of TSM after the injection of gadoxetate disodium at a German institution without identifying a potential risk factor for this phenomenon. The frequency of TSM was higher for gadoxetate disodium compared to gadobenate dimeglumine. Interestingly, the overall frequency of respiratoryrelated artifacts in non-arterial contrast phases was higher for gadobenate dimeglumine than for gadoxetate disodium.

Our results regarding the higher frequency of TSM after the injection of gadoxetate disodium compared to gadobenate dimeglumine confirm previous observations from the USA and Japan [15 - 17, 20, 21]. However, the frequency of TSM observed in our study and previous studies has a high variability, ranging from $5 \%$ to $22 \%$. On one hand, our observed rate of TSM (21\%) after the injection of gadoxetate disodium is similar to the rate reported by Motosugi et al. (22\%) [17] and Davenport et al. (17\%) [15]. On the other hand, these high rates of TSM are at least twice as high as the results of Pietryga et al. (11\%) [16], Hayashi et al. (5\%) [21], and Kim et al. (13\%) [20] ( $>$ Table 4).

These different rates of TSM are interesting observations, as they might help to identify underlying reasons or risk factors for this phenomenon. It is tempting to assume that investigation of a less healthy patient collective might result in an increased frequency of TSM. Indeed, this seems to be the case when comparing our high rate of TSM and high incidence of potential risk factors with the low rate of TSM and the low incidence of potential risk factors in the study of Hayashi et al. [21]. However, this speculation is disproved when comparing our observations with the low rate of TSM but high incidence of potential risk factors in the study of Pietryga et al. [16].

In our study, the frequency of respiratory imaging artifacts was higher for each of the four imaging phases in the gadobenate dimeglumine group than in the gadoxetate disodium group. Interestingly, in the gadobenate dimeglumine group, also the 
- Table 2 Mean motion scores according to imaging phase and contrast agent.

- Tab. 2 Bewertung der Atemartefakte nach Phase und verwendetem Kontrastmittel.

\begin{tabular}{|c|c|c|c|c|c|c|c|c|c|}
\hline & \multirow[b]{2}{*}{ phase } & \multicolumn{4}{|c|}{$\begin{array}{l}\text { gadoxetate disodium } \\
\qquad(n=89)\end{array}$} & \multicolumn{4}{|c|}{$\begin{array}{l}\text { gadobenate dimeglumine } \\
\qquad(n=89)\end{array}$} \\
\hline & & pre & art & ven & late & pre & art & ven & late \\
\hline \multirow{8}{*}{$\begin{array}{l}\text { motion } \\
\text { score }\end{array}$} & \multirow{2}{*}{1} & $46.1 \%$ & $29.2 \%$ & $52.8 \%$ & $56.2 \%$ & $31.5 \%$ & $33.7 \%$ & $39.3 \%$ & $37.1 \%$ \\
\hline & & $(41 / 89)$ & $(26 / 89)$ & $(46 / 89)$ & $(49 / 89)$ & $(28 / 89)$ & (30/89) & $(35 / 89)$ & $(33 / 89)$ \\
\hline & \multirow{2}{*}{2} & $44.9 \%$ & $36.0 \%$ & $37.1 \%$ & $37.1 \%$ & $44.9 \%$ & $47.2 \%$ & $39.3 \%$ & $38.2 \%$ \\
\hline & & $(40 / 89)$ & $(32 / 89)$ & $(33 / 89)$ & (33/89) & $(40 / 89)$ & $(42 / 89)$ & $(35 / 89)$ & $(34 / 89)$ \\
\hline & \multirow{2}{*}{3} & $9.0 \%$ & $25.8 \%$ & $9.0 \%$ & $6.7 \%$ & $18.0 \%$ & $13.5 \%$ & $15.7 \%$ & $18.0 \%$ \\
\hline & & $(8 / 89)$ & $(23 / 89)$ & $(8 / 89)$ & $(6 / 89)$ & (16/89) & $(12 / 89)$ & $(14 / 89)$ & (16/89) \\
\hline & \multirow{2}{*}{4} & $0 \%$ & $9.0 \%$ & $1.1 \%$ & $0 \%$ & $5.6 \%$ & $5.6 \%$ & $5.6 \%$ & $6.7 \%$ \\
\hline & & $(0 / 89)$ & $(8 / 89)$ & $(1 / 89)$ & $(0 / 89)$ & $(5 / 89)$ & $(5 / 89)$ & $(5 / 89)$ & $(6 / 89)$ \\
\hline
\end{tabular}

- Table 3 Results of logistic regression analysis of potential risk factors and TSM.

- Tab. 3 Ergebnisse logistischer Regression potentieller Risikofaktoren und TSA.

\begin{tabular}{|c|c|c|c|c|}
\hline characteristics & $\begin{array}{l}\text { gadoxetate disodium TSM } \\
(n=19)\end{array}$ & p-value & $\begin{array}{l}\text { gadobenate dimeglumine TSM } \\
(n=1)\end{array}$ & p-value \\
\hline \multicolumn{5}{|l|}{ sex } \\
\hline - male & $11(57.9 \%)$ & 0.552 & $1(100 \%)$ & 0.448 \\
\hline - female & $8(42.1 \%)$ & 0.552 & - & 0.448 \\
\hline mean age (years) & $57.8 \pm 12.1(35.0-74.0)$ & 0.461 & 65 & 0.576 \\
\hline mean body mass index $\left(\mathrm{kg} / \mathrm{m}^{2}\right)$ & $27.3 \pm 4.9(21.2-37.0)$ & 0.176 & 25.0 & 0.913 \\
\hline mean volume of contrast agent (ml) & $8.5 \pm(4-10)$ & 0.062 & 10 & 0.946 \\
\hline ascites & $1(5.3 \%)$ & 0.627 & $0(0 \%)$ & 0.903 \\
\hline pleural effusions & $1(5.3 \%)$ & 0.607 & $0(0 \%)$ & 0.862 \\
\hline lung disease & $4(21.1 \%)$ & 0.05 & $0(0 \%)$ & 0.778 \\
\hline previous exposure to contrast agent & $4(21.1 \%)$ & 0.616 & $0(0 \%)$ & 0.335 \\
\hline allergies & $5(26.3 \%)$ & 0.466 & $0(0 \%)$ & 0.535 \\
\hline liver cirrhosis & $4(21.1 \%)$ & 0.924 & $0(0 \%)$ & 0.778 \\
\hline hepatocellular carcinoma & $2(10.5 \%)$ & 0.556 & $0(0 \%)$ & 0.830 \\
\hline hypertension & $7(36.8 \%)$ & 0.389 & $0(0 \%)$ & 0.462 \\
\hline
\end{tabular}

pre-contrast images had a high frequency of respiratory artifacts, indicating that this observation is not related to gadobenate dimeglumine. We also do not think that this result of our study is caused by a subjective observer bias of the readers, since the overall interobserver agreement of motion scores was high for all imaging phases. While the frequency of TSM caused by gadobenate dimeglumine in our study is similar to previously published data $(0.5-2 \%)$, the overall high number of respiratory artifacts in non-arterial phases in our study differs from other studies [15, 16]. We were not able to identify the underlying reason for this observation. However, we assume that the overall higher frequency of respiratory artifacts may be due to patients being less healthy in the gadobenate dimeglumine group.

Our study showed no significant correlation of TSM with any of the obtained patient characteristics or potential risk factors, which is in accordance with the observation of Kim et al. [20]. 
Table 4 Frequency of TSM after injection of gadoxetate disodium and patient characteristics of different studies.

- Tab.4 Häufigkeit von TSA nach Injektion von Dinatriumgadoxetat und Patientencharakteristika ausgewählter Studien.

\begin{tabular}{|c|c|c|c|c|c|c|c|}
\hline \multirow[t]{2}{*}{ author } & \multirow[t]{2}{*}{ our study } & \multirow[t]{2}{*}{ Davenport et al. } & \multirow[t]{2}{*}{ Pietryga et al. } & \multirow[t]{2}{*}{ Kim et al. } & \multirow[t]{2}{*}{ Hayashi et al. } & \multicolumn{2}{|c|}{ Motosugi et al. } \\
\hline & & & & & & Site A & Site B \\
\hline publication date & & 2013 & 2014 & 2015 & 2015 & 2016 & \\
\hline journal & & Radiology & Radiology & Gast Im & Radiology & \multicolumn{2}{|c|}{ Radiology } \\
\hline country & Germany & USA & USA & USA & Japan & USA & Japan \\
\hline TSM & $\begin{array}{l}19 / 89 \\
(21.3 \%)\end{array}$ & $\begin{array}{l}17 / 99 \\
(17.2 \%)\end{array}$ & $\begin{array}{l}37 / 345 \\
(10.7 \%)\end{array}$ & $\begin{array}{l}46 / 357 \\
(12.9 \%)\end{array}$ & $\begin{array}{l}22 / 458 \\
(4.8 \%)\end{array}$ & $\begin{array}{l}32 / 146 \\
(21.9 \%)\end{array}$ & $\begin{array}{l}17 / 130 \\
(13.1 \%)\end{array}$ \\
\hline $\begin{array}{l}\text { dosing of contrast agent/ } \\
\text { concentration }\end{array}$ & $\begin{array}{l}\text { weight-based/ } \\
0.025 \mathrm{mmol} \\
\text { per kg }\end{array}$ & fixed $(10 \mathrm{ml})$ & fixed $(10 \mathrm{ml})$ & fixed $(10 \mathrm{ml})$ & $\begin{array}{l}\text { weight-based/ } \\
0.025 \mathrm{mmol} \text { per } \\
\text { kg (max. } 10 \mathrm{ml})\end{array}$ & $\begin{array}{l}\text { weight-based/ } \\
0.05 \mathrm{mmol} \\
\text { per kg }\end{array}$ & $\begin{array}{l}\text { weight-based/ } \\
0.025 \mathrm{mmol} \\
\text { per kg }\end{array}$ \\
\hline $\begin{array}{l}\text { mean volume of } \\
\text { contrast agent ( } \mathrm{ml})\end{array}$ & 8.08 & 10.0 & 10.0 & 10.0 & - & - & - \\
\hline $\begin{array}{l}\text { injection/ } \\
\text { injection rate/ } \\
\text { saline flush }\end{array}$ & $\begin{array}{l}\text { manually } \\
2 \mathrm{ml} \mathrm{per} \mathrm{sec} \\
+20 \mathrm{ml}\end{array}$ & $\begin{array}{l}\text { power injected } \\
2 \mathrm{ml} \text { or } 1 \mathrm{ml} \text { per sec } \\
+ \text { equal amount }\end{array}$ & $\begin{array}{l}\text { power injected } \\
2 \mathrm{ml} \mathrm{per} \mathrm{sec} \\
+20 \mathrm{ml}\end{array}$ & $\begin{array}{l}\text { power injected } \\
1 \mathrm{ml} \text { per sec } \\
+25 \mathrm{ml}\end{array}$ & $\begin{array}{l}\mathrm{n} / \mathrm{a} \\
1 \mathrm{ml} \text { per sec } \\
+40 \mathrm{ml}\end{array}$ & $\begin{array}{l}\mathrm{n} / \mathrm{a} \\
2 \mathrm{ml} \text { per sec } \\
+50 \mathrm{ml}\end{array}$ & $\begin{array}{l}\mathrm{n} / \mathrm{a} \\
1 \mathrm{ml} \text { per sec } \\
+20 \mathrm{ml}\end{array}$ \\
\hline $\begin{array}{l}\text { arterial phase } \\
\text { acquisition time (s) }\end{array}$ & $12-15$ & $18-22$ & $3 \times 7.5$ & 16 & 20 & $20 / 22$ & 16 \\
\hline mean age (years) & $55.2 \pm 15.2$ & $\begin{array}{l}56 \text { male/ } \\
58 \text { female }\end{array}$ & 54.8 & $\begin{array}{l}64 \pm 7 \text { TSM/ } \\
62 \pm 8 \text { non } \\
\text { TSM }\end{array}$ & $\begin{array}{l}61.1 \pm 15.5 \text { TSM/ } \\
63.2 \pm 12.5 \text { non } \\
\text { TSM }\end{array}$ & $52.0 \pm 15.2$ & $51.9 \pm 15.1$ \\
\hline mean BMI $\left(\mathrm{kg} / \mathrm{m}^{2}\right)$ & $26.31 \pm 4.9$ & 29 & 28.3 & $\begin{array}{l}27 \pm 5 / \\
29 \pm 6\end{array}$ & $\begin{array}{l}24.3 \pm 3.9 / \\
23.4 \pm 3.9\end{array}$ & $\mathrm{n} / \mathrm{a}$ & $\mathrm{n} / \mathrm{a}$ \\
\hline ascites & $7 / 89(7.9 \%)$ & $34 / 99$ (34.3\%) & $29 / 345$ (8.4\%) & $30 / 357(8.4 \%)$ & $12 / 458(2.6 \%)$ & $5 / 146(3.4 \%)$ & $5 / 130(3.8 \%)$ \\
\hline pleural effusion & $3 / 89(3.4 \%)$ & 7/99 (7.1\%) & $23 / 345$ (6.7\%) & $11 / 357(3.1 \%)$ & $8 / 458(1.7 \%)$ & $4 / 146$ (2.7\%) & 4/130 (3.1\%) \\
\hline lung disease & $\begin{array}{l}9 / 89 \\
(10.1 \%)\end{array}$ & $\begin{array}{l}8 / 99 \\
(8.1 \%)\end{array}$ & $\begin{array}{l}48 / 345 \\
(13.9 \%)\end{array}$ & $\begin{array}{l}30 / 357 \\
(8.4 \%)\end{array}$ & $\begin{array}{l}12 / 458 \\
(2.6 \%)\end{array}$ & $\begin{array}{l}20 / 146 \\
(13.7 \%)\end{array}$ & $\begin{array}{l}17 / 130 \\
(13.1 \%)\end{array}$ \\
\hline previous exposure & $\begin{array}{l}22 / 89 \\
(24.7 \%)\end{array}$ & $\mathrm{n} / \mathrm{a}$ & 0 & $\begin{array}{l}137 / 357 \\
(38.4 \%)\end{array}$ & $\begin{array}{l}322 / 458 \\
(70.3 \%)\end{array}$ & 0 & 0 \\
\hline allergies & $\begin{array}{l}17 / 89 \\
(19.1 \%)\end{array}$ & $\begin{array}{l}23 / 99 \\
(23.2 \%)\end{array}$ & $\mathrm{n} / \mathrm{a}$ & $\begin{array}{l}10 / 357 \\
(2.8 \%)^{1}\end{array}$ & $\begin{array}{l}9 / 458 \\
(2.0 \%)\end{array}$ & $\begin{array}{l}83 / 146 \\
(56.8 \%)\end{array}$ & $\begin{array}{l}75 / 130 \\
(57.7 \%)\end{array}$ \\
\hline chronic liver disease & $\begin{array}{l}22 / 89 \\
(24.7 \%)\end{array}$ & $\begin{array}{l}72 / 99 \\
(72.7 \%)\end{array}$ & $\begin{array}{l}141 / 345 \\
(40.9 \%)\end{array}$ & $\begin{array}{l}262 / 357 \\
(73.4 \%)\end{array}$ & $\begin{array}{l}419 / 458 \\
(91.5 \%)\end{array}$ & $\begin{array}{l}7 / 146 \\
(4.8 \%)\end{array}$ & $\begin{array}{l}7 / 130 \\
(5.4 \%)\end{array}$ \\
\hline hepatocellular carcinoma & $\begin{array}{l}13 / 89 \\
(14.6 \%)\end{array}$ & $\begin{array}{l}22 / 99 \\
(22.2 \%)\end{array}$ & $\mathrm{n} / \mathrm{a}$ & $\begin{array}{l}124 / 357 \\
(34.7 \%)\end{array}$ & $\mathrm{n} / \mathrm{a}$ & $\mathrm{n} / \mathrm{a}$ & $\mathrm{n} / \mathrm{a}$ \\
\hline hypertonus & $\begin{array}{l}29 / 89 \\
(32.6 \%)\end{array}$ & $\mathrm{n} / \mathrm{a}$ & $\mathrm{n} / \mathrm{a}$ & $\begin{array}{l}139 / 357 \\
(38.9 \%)\end{array}$ & $\mathrm{n} / \mathrm{a}$ & $\begin{array}{l}24 / 146 \\
(16.4 \%)^{2}\end{array}$ & $\begin{array}{l}21 / 130 \\
(16.2 \%)^{2}\end{array}$ \\
\hline
\end{tabular}

Percentages are rounded.

Prozentangaben gerundet.

1 Allergy against iodinated contrast agent.

Allergie gegen jodhaltiges Kontrastmittel.

2 Cardiac condition.

Kardiale Erkrankung.

The high incidence of hepatic disease in patients who were injected with gadoxetate disodium might suggest a correlation with TSM. We were not able to prove this hypothesis, which is in accordance with previous studies [17, 30]. Furthermore, a recently published study on TSA in exclusively cirrhotic patients did not show an increased frequency of TSA compared to other studies
[30]. However, other authors have identified the following risk factors in previous studies: applied dose of contrast agent, lung disease [18], repeated dosing of contrast agent [19], male sex or high BMI [17]. The lack of a correlation between the applied dose of gadoxetate disodium and TSM in our study might be explained by the weight-based application $(0.025 \mathrm{mmol} / \mathrm{kg})$ in our institu- 
tion. Other hospitals apply higher, fixed off-label doses up to $20 \mathrm{ml}$ to improve arterial phase contrast [18]. The number of patients in our study who received repeated dosing of the same contrast agent was low compared to previous studies. This might explain why we were not able to confirm repeated dosing as a risk factor, which has been indicated previously [19]. Another potential cause for TSM might be a sudden onset of nausea after injection of gadoxetate disodium. However, previous studies did not find a relevant difference in frequency of nausea between gadoxetate disodium and gadobenate dimeglumine [17]. The only risk factor in our study that showed a trend towards significance was the prevalence of lung disease, which supports previous observations by Davenport et al. [18].

As the underlying cause of TSM remains unclear and because arterial phase imaging is essential for characterizing focal liver lesions [27-29], strategies to minimize the frequency or extent of TSM must be developed. Shortening acquisition time is one strategy to minimize the effect of TSM during gadoxetate disodium-enhanced liver MRI. In our study the breath-hold duration ranged from 12 to 15 seconds, which is slightly shorter compared to previous studies that reported comparable frequencies of TSM $[15,17]$. In this regard, Pietryga et al. were able to significantly reduce the effects of TSM during arterial phase imaging by reducing the acquisition time to 7.5 seconds [16]. This notion is supported by a recently published prospective study that compared the maximal breath-hold duration and frequency of motion artifacts after injection of gadoxetate disodium, gadobenate dimeglumine, and normal saline [26]. In this study, the injection of gadoxetate disodium led to a significant reduction of the maximal breath-hold duration, which in turn was associated with motion artifacts. Thus, marked shortening of the scan time seems a reasonable approach to minimize the frequency and/or extent of TSM. However, a reduction of scan time with currently widely available standard techniques will decrease spatial resolution and signal-to-noise ratio. Additionally, the risk of poorly timed arterial phase imaging is increased.

A limitation of our study, as for most of the previous studies, is the retrospective design, which precluded $\mathrm{SpO}_{2}$ monitoring or recording of patient questionnaires as performed by Motosugi et al. [17]. Moreover, the number of included patients was adequate for comparison of the frequency of TSM. However, for the identification of risk factors for TSM, it might be too low, due to small numbers of positive cases for some of the potential risk factors. Therefore, these results should be assessed with caution and future studies need to include larger numbers to identify risk factors for TSM.

Another limitation of our and previous retrospective studies is that we were not able to assess if the motion artifacts after the injection of gadoxetate disodium during the arterial phase hamper the diagnostic accuracy of the entire MRI examination. Arterial enhancement is an important feature for the diagnosis of HCC and other arterially enhancing lesions, but these lesions show also other features, which are displayed in additional sequences. However, a thorough assessment of a diagnosis-limiting effect of TSM on the arterial phase requires a prospective study that fulfills two major prerequisites: First, an intra-patient comparison with both an extracellular gadolinium-based contrast agent (GBCA) and gadoxetate disodium is required. Only this comparative analysis will allow assessment of whether arterially enhancing lesions (i.e., HCC) are present with the extracellular GBCA and if these lesions are then missed or detected with gadoxetate disodium in cases of TSM, and lastly, if this has an impact on the diagnostic accuracy of the entire study. Second, all identified lesions need histopathological confirmation for validation. Moreover, since only up to one-fifth of patients have TSM, a large patient population is needed to answer this question in such a prospective study design.

Our confirmation of a high rate of TSM (up to $~ 20 \%$ ) has important clinical implications. As mentioned above, the acquisition of arterial phases is of particular importance for the characterization of hypervascularized lesions [12-14]. Indeed, arterial enhancement is a hallmark imaging feature to establish the diagnosis of HCC [22 - 24]. However, the effect of TSM on diagnostic accuracy remains unclear. Therefore, one has to weigh potential drawbacks of gadoxetate disodium (lack of arterial phase information) against its benefits (improved lesion detection in the hepatobiliary phase) until future studies confirm or exclude an effect on diagnostic accuracy. Additionally, implementation of shorter arterial phase protocols may be considered [16, 25].

In summary, we confirmed at a German institution that TSM during the arterial phase of gadoxetate disodium occurs in up to one-fifth of patients undergoing gadoxetate disodium-enhanced liver MRI. However, we were not able to confirm or identify new possible risk factors for TSM. Hence, the reason for arterial phase TSM remains unclear and the usage of gadoxetate disodium-enhanced liver MRI should be carefully considered in the setting of hypervascularized lesions such as HCC.

\section{CLINICAL RELEVANCE}

- Gadoxetate disodium causes potentially diagnosis-limiting transient severe respiratory motion artifacts in a relevant number of patients.

- Patients with pulmonary disease, high doses of applied contrast agent, repeated dosing or high body mass index are more likely to suffer from transient severe motion artifacts.

- Due to the frequency of transient severe respiratory motion artifacts, adjustment of arterial phase protocols and careful evaluation of applied contrast agents should be considered.

\section{Conflict of Interest}

No conflict of interest has been declared by the author(s).

\section{References}

[1] Hamm B, Staks T, Muhler A et al. Phase I clinical evaluation of Gd-EOBDTPA as a hepatobiliary MR contrast agent: safety, pharmacokinetics, and MR imaging. Radiology 1995; 195: 785-792 
[2] Reimer P, Rummeny E], Shamsi K et al. Phase II clinical evaluation of Gd-EOB-DTPA: dose, safety aspects, and pulse sequence. Radiology 1996; 199: $177-183$

[3] Bluemke DA, Sahani D, Amendola M et al. Efficacy and safety of MR imaging with liver-specific contrast agent: U.S. multicenter phase III study. Radiology 2005; 237: 89-98

[4] Dohr O, Hofmeister R, Treher M et al. Preclinical safety evaluation of Gd-EOB-DTPA (Primovist). Invest Radiol 2007; 42: 830-841

[5] Kirchin MA, Pirovano G, Venetianer C et al. Safety assessment of gadobenate dimeglumine (MultiHance): extended clinical experience from phase I studies to post-marketing surveillance. J Magn Reson Imaging 2001; 14: $281-294$

[6] Park M], Kim YK, Lee MW et al. Small hepatocellular carcinomas: improved sensitivity by combining gadoxetic acid-enhanced and diffusionweighted MR imaging patterns. Radiology 2012; 264: 761 - 770

[7] Sano K, Ichikawa T, Motosugi U et al. Imaging study of early hepatocellular carcinoma: usefulness of gadoxetic acid-enhanced MR imaging. Radiology 2011; 261: 834-844

[8] Armbruster M, Zech C], Sourbron S et al. Diagnostic accuracy of dynamic gadoxetic-acid-enhanced MRI and PET/CT compared in patients with liver metastases from neuroendocrine neoplasms. J Magn Reson Imaging 2014; 40: 457-466

[9] Jeong HT, Kim M, Park M et al. Detection of liver metastases using gadoxetic-enhanced dynamic and 10- and 20-minute delayed phase MR imaging. J Magn Reson Imaging 2012; 35: 635-643

[10] Muhi A, Ichikawa T, Motosugi U et al. Diagnosis of colorectal hepatic metastases: comparison of contrast-enhanced CT, contrast-enhanced US, superparamagnetic iron oxide-enhanced MRI, and gadoxetic acidenhanced MRI. J Magn Reson Imaging 2011; 34: 326-335

[11] Frydrychowicz A, Lubner MG, Brown J] et al. Hepatobiliary MR imaging with gadolinium-based contrast agents. J Magn Reson Imaging 2012; 35: $492-511$

[12] Zech C], Vos B, Nordell A et al. Vascular enhancement in early dynamic liver MR imaging in an animal model: comparison of two injection regimen and two different doses Gd-EOB-DTPA (gadoxetic acid) with standard Gd-DTPA. Invest Radiol 2009; 44: 305-310

[13] Motosugi U, Ichikawa T, Araki T. Rules, roles, and room for discussion in gadoxetic acid-enhanced magnetic resonance liver imaging: current knowledge and future challenges. Magn Reson Med Sci 2013; 12: 161 175

[14] Bruix J, Reig M, Rimola J et al. Clinical decision making and research in hepatocellular carcinoma: pivotal role of imaging techniques. Hepatology 2011; 54: $2238-2244$

[15] Davenport MS, Viglianti BL, Al-Hawary MM et al. Comparison of Acute Transient Dyspnea after Intravenous Administration of Gadoxetate Disodium and Gadobenate Dimeglumine: Effect on Arterial Phase Image Quality. Radiology 2013; 266: $452-461$

[16] Pietryga JA, Burke LMB, Marin D et al. Respiratory Motion Artifact Affecting Hepatic Arterial Phase Imaging with Gadoxetate Disodium: Examination Recovery with a Multiple Arterial Phase Acquisition. Radiology 2014; 271: 426-434
[17] Motosugi U, Bannas P, Bookwalter CA et al. An Investigation of Transient Severe Motion Related to Gadoxetic Acid-enhanced MR Imaging. Radiology 2016; 279: 93-102

[18] Davenport MS, Bashir MR, Pietryga JA et al. Dose-Toxicity Relationship of Gadoxetate Disodium and Transient Severe Respiratory Motion Artifact. American Journal of Roentgenology 2014; 203: 796-802

[19] Bashir MR, Castelli P, Davenport MS et al. Respiratory motion artifact affecting hepatic arterial phase MR imaging with gadoxetate disodium is more common in patients with a prior episode of arterial phase motion associated with gadoxetate disodium. Radiology 2015; 274: 141 - 148

[20] Kim SY, Park SH, Wu E et al. Transient Respiratory Motion Artifact During Arterial Phase MRI With Gadoxetate Disodium: Risk Factor Analyses. American Journal of Roentgenology 2015; 204: 1220-1227

[21] Hayashi T, Saitoh S, Tsuji Y et al. Influence of Gadoxetate Disodium on Oxygen Saturation and Heart Rate during Dynamic Contrast-enhanced MR Imaging. Radiology 2015; 276: 756-765

[22] Becker-Weidman DJS, Kalb B, Sharma P et al. Hepatocellular Carcinoma Lesion Characterization: Single-Institution Clinical Performance Review of Multiphase Gadolinium-enhanced MR Imaging-Comparison to Prior Same-Center Results after MR Systems Improvements. Radiology 2011; 261: $824-833$

[23] Choi SH, Lee JM, Yu NC et al. Hepatocellular carcinoma in liver transplantation candidates: detection with gadobenate dimeglumine-enhanced MRI. Am J Roentgenol 2008; 191: 529- 536

[24] Wald C, Russo MW, Heimbach JK et al. New OPTN/UNOS policy for liver transplant allocation: standardization of liver imaging, diagnosis, classification, and reporting of hepatocellular carcinoma. Radiology 2013; 266: $376-382$

[25] McKenzie CA, Lim D, Ransil B] et al. Shortening MR image acquisition time for volumetric interpolated breath-hold examination with a recently developed parallel imaging reconstruction technique: clinical feasibility. Radiology 2004; 230: 589 - 594

[26] McClellan TR, Motosugi U et al. Intravenous Gadoxetate Disodium Administration Reduces Breath-holding Capacity in the Hepatic Arterial Phase: A Multi-center Randomized Placebo-controlled Trial. Radiology 2017; 282: $361-368$

[27] Bartolozzi C, Battaglia V et al. Contrast-enhanced magnetic resonance imaging of 102 nodules in cirrhosis: correlation with histological findings on explanted livers. Abdom Imaging 2013; 38: 290-296

[28] Morana G, Grazioli L et al. Solid hypervascular liver lesions: accurate identification of true benign lesions on enhanced dynamic and hepatobiliary phase magnetic resonance imaging after gadobenate dimeglumine administration. Invest Radiol 2011; 46: 225 - 239

[29] Hussain SM, Reinhold C et al. Cirrhosis and lesion characterization at MR imaging. RadioGraphics 2009; 29: 1637 - 1652

[30] Furlan A, Close ON et al. Respiratory-motion artefacts in liver MRI following injection of gadoxetate disodium and gadobenate dimeglumine: an intra-individual comparative study in cirrhotic patients. Clin Radiology $2017 ; 72: 93 e 1-93 e 6$ 